\title{
A Preliminary Study of the Pseudobranch Associated with the Spiracle in the North American Paddlefish, Polyodon spathula
}

\author{
K.M. Maroni*, R.L. Sherman**, R.E. Spieler* \\ * Oceanographic Center, Nova Southeastern University, Dania Beach, FL 33004 \\ ** Farquhar College of Arts and Sciences, Nova Southeastern University, Davie, FL 33314
}

A pseudobranch, a small gill-like organ, can be found in most fishes including Elasmobranchii, Chondrostei, and Teleostei, however, the exact location varies among the groups. The function of the pseudobranch is not clear although it is likely not primarily for oxygen exchange as it receives blood directly from the gills. We examined the vascular supply of the pseudobranch of Polyodon spathula as an initial study on the physiologic function of this organ in paddlefish.

The pseudobranch associated with the spiracle in $P$. spathula was observed using Mercox ${ }^{\circledR}$ corrosion casts and light microscopy. The pseudobranch is supplied via the afferent pseudobranchial artery (APA) which stems from the efferent branchial artery of the first gill. The APA progresses dorsal and posteriorly before making a turn anterior and finally bifurcating into posterior and anterior divisions on the ventral surface of the pseudobranch. In this specimen, the posterior segment of the APA gives off eight filamentar arteries while the anterior segment gives off sixteen filamentar arteries (Fig. 1A). The efferent filamentar arteries gather dorsally on the pseudobranch into the efferent pseudobranchial artery (EPA) which turns ventral and proceeds anteriorly (Fig. 1B). The EPA connects with the internal carotid (IC) after giving off a branch to the ophthalmica magna artery (OM) (Fig. 2C). The internal carotid continues medially and craniad.

Gross anatomical examination of the arteries leading to and from the pseudobranch was completed by Danforth (1912). Based on the corrosion cast, we noted some variations to the Danforth study. Danforth $^{[1]}$ reported a reduction in size of the EPA after anastomosis with the IC, which then continues as the OM. However, the corrosion cast clearly shows the OM diverging from the EPA before the connection with the IC (Fig. 2D). This organization is similar to that found in the white sturgeon, Acipenser transmontanus ${ }^{[2]}$. Also, contrary to Danforth (1912) the only reduction in vessel diameter observed in our study is the OM and the EPA does not reduce in diameter but may completely merge with the IC after giving off the OM. Since slight variations in vascular arrangement are common, the connection between the EPA, IC and OM will be further studied using SEM to determine their spatial arrangement in this specimen. Additional specimens will be examined to determine the extent of variation within the species.

\section{References}

[1] C.H. Danforth, The Anatomy of Polyodon, Washington University, Saint Louis, 1913.

[2] W. Burggren et al., Can. J. Zool. 57 (1979) 2160-2170.

Acknowledgement: The assistance of A.T. St. Gelais with the micrographs is greatly appreciated. 

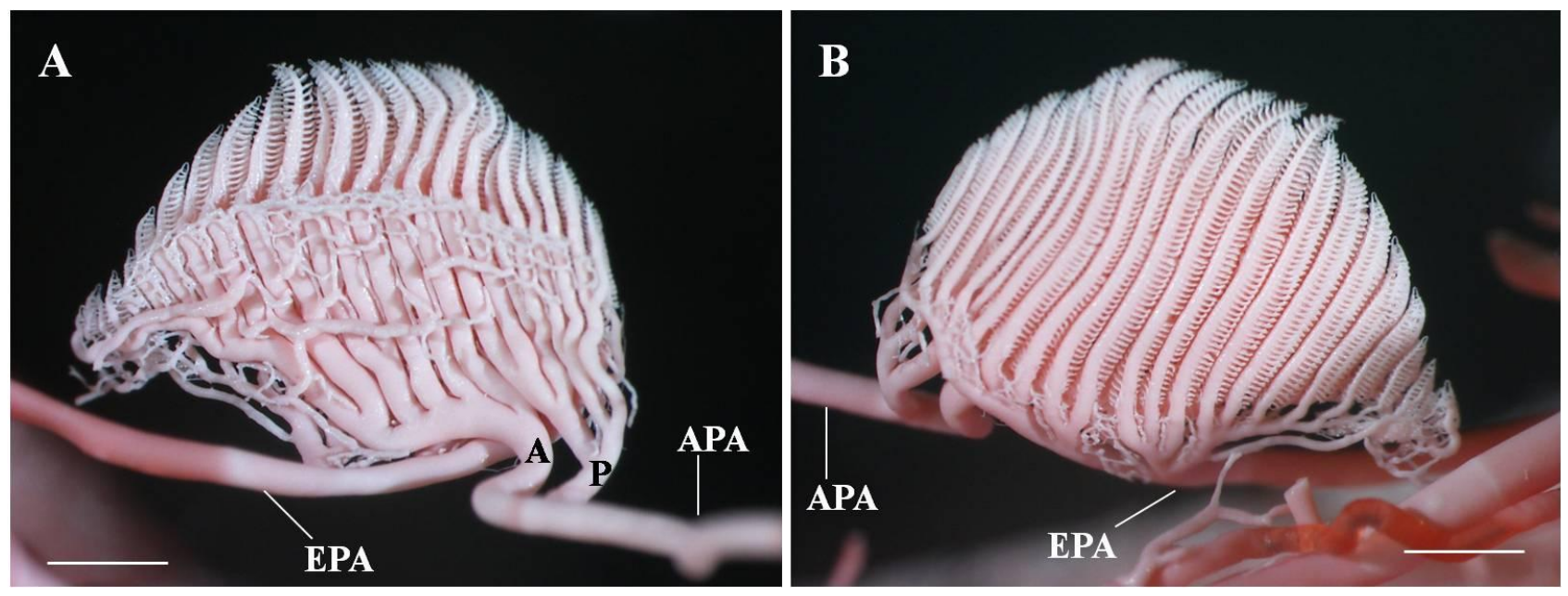

FIG. 1. Ventral (A) and dorsal (B) view of the pseudobranch in Polyodon spathula (EPA: efferent pseudobranchial artery; APA: afferent pseudobranchial artery; A: anterior; P: posterior). (Bar= $1 \mathrm{~mm})$
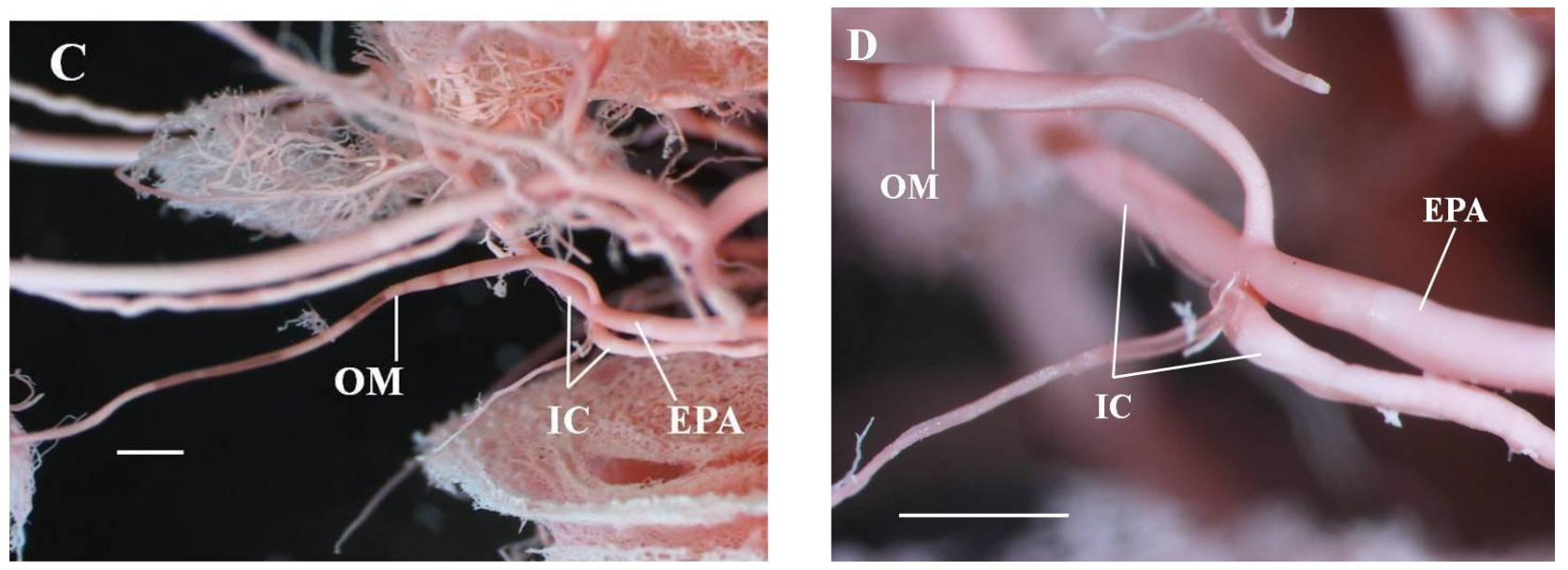

FIG. 2. Lateral view (C) of efferent pseudobranchial artery (EPA), ophthalmica magna artery (OM) and internal carotid (IC), and magnified view (D) of the connection between these vessels. $($ Bar $=$ $1 \mathrm{~mm})$ 